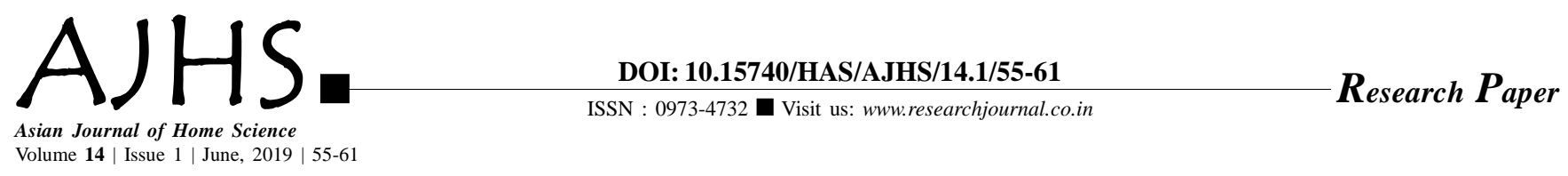

\title{
Impact of special education on management of adjustment problems faced by children with learning disability
}

\author{
P. Neeraja and K. Anuradha
}

Received: 20.10.2018; Revised: 11.04.2019; Accepted: 21.04.2019

See end of the paper for authors' affiliations

\section{P. Neeraja}

Department of Home Science S.V.University, Tirupati (A.P.) India
ABSTRACT : During elementary school age, children learn about the wider world and master improved athletic abilities, participation in games with rules, more logical thought processes, mastery of basic literacy skills and advances in self-understanding, morality and friendship (Berk, 2003).The development during elementary school age has considerable significance for behavior pattern and adjustment for later stages.Learning disability, an unexplained difficulty experienced by children of at least average intelligence in acquiring basic academic skills usually identified during elementary school age.The study sample were elementary school children selected from Hyderabad, Nellore and Chittoor districts of united state of Andhra Pradesh representing three regions of the state i.e. Rayalaseema, Costal region and Telangana. Total sample were 120 children with LD attending special education (60) and not attending special education (60). In this study found that the prevalence of learning disability was more among boys than girls and among first born children and had average intelligence. Parents of children with LD perceived more stressful emotional reactions of about their children's adjustments and the mean scores showed that parents perceived less stress for children who were attending full time SE classes than those attending classes in resource rooms.

KEY WORDS: Special education, Management, Adjustment, Problems faced, Children

- HOW TO CITE THIS PAPER : Neeraja, P. and Anuradha, K. (2019). Impact of special education on management of adjustment problems faced by children with learning disability. Asian J. Home Sci., 14 (1) : 55-61, DOI: 10.15740/HAS/AJHS/14.1/55-61. Copyright@ 2019: Hind Agri-Horticultural Society. 